\title{
The Potential of RNA Vaccines for Infectious Diseases and COVID-19
}

\author{
Kenneth Lundstrom*
}

PanTherapeutics, Rte de Lavaux 49, CH1095 Lutry, Switzerland

\begin{tabular}{|c|c|}
\hline A R T I C L E I N F O & A B S T R A C T \\
\hline Review Article & $\begin{array}{l}\text { In addition to conventional vaccine development for infectious diseases, nucleic acid- } \\
\text { based vaccine approaches have recently been presented as serious alternatives to }\end{array}$ \\
\hline VacRes, 2020 & previously used strategies based on live attenuated virus particles and subunit vaccines. \\
\hline Vol. 7 , No. $1,25-37$ & Particularly, RNA-based vaccines have proven attractive. In this context, immunization \\
\hline Received: July 17, 2020 & with messenger RNA (mRNA) has provided strong immune responses and protection \\
\hline Accepted: August 01, 2020 & against challenges with lethal doses of pathogenic viruses in vaccinated animals. \\
\hline Pasteur Institute of Iran & Alternatively, the efficient RNA replication mechanism provided by self-amplifying RNA \\
\hline *Corresponding Author: & (saRNA) viruses has been utilized. Enhanced immune responses with reduced doses \\
\hline PanTherapeutics, Rte de Lavaux 49, & administration. The rapid spread and destruction caused by the COVID-19 pandemic has \\
\hline Email: lundstromkenneth@gmail.com & substantially accelerated the demand for the development of robust and efficient vaccines \\
\hline Tel/Fax: $(+41) 797766351$ & $\begin{array}{l}\text { against SARS-CoV-2. Both mRNA- and saRNA-based COVID-19 vaccine candidates are } \\
\text { currently in human clinical trials. }\end{array}$ \\
\hline $\begin{array}{l}\text { KEYWORDS: RNA vectors; RNA } \\
\text { replicons; RNA vaccines; immune } \\
\text { responses; protection against } \\
\text { pathogens; coronaviruses; COVID-19 }\end{array}$ & $\begin{array}{l}\text { Citation: } \\
\text { Lundstrom K. The Potential of Self-amplifying RNA Vaccines for Infectious Diseases and } \\
\text { COVID-19. vacres. 2020; } 7 \text { (1) :25-37. DOI: 10.29252/vacres.7.1.25 }\end{array}$ \\
\hline
\end{tabular}

\section{INTRODUCTION}

In search for alternative vaccine development methods to conventional live attenuated viruses and subunit vaccines based on recombinant protein expression, nucleic acids have been investigated as delivery and expression vehicles [1]. In this context, DNA vaccines have proven to be safe with only few side effects and improvements have been demonstrated by application of nanoparticles and electroporation for delivery and enhanced immunogenicity by addition of suitable adjuvants [2]. Moreover, it has been shown that intracutaneous injection of DNA is superior to intramuscular or subcutaneous administration. More recently, RNA-based vaccines have become attractive as delivery vehicles for vaccines. RNA-based vaccines have become potentially promising as alternative approaches to conventional vaccine development [3]. The advantage of RNA-based immunizations compared to administration of DNA is the immediate translation of mRNA in the cytoplasm, omitting the step of inefficient delivery to the nucleus [4]. However, in contrast to plasmid DNA, single stranded mRNA molecules are substantially more prone to degradation. A potentially attractive approach for RNA-based vaccines is to apply self-amplifying RNA (saRNA) viruses as they can provide extensive replication of the delivered RNA in the cytoplasm, thereby significantly enhancing the mRNA population resulting in stronger antigen production and elevated immune responses. In this review, the focus is on saRNA viruses as delivery vectors for vaccine development to target infectious diseases although they have also been frequently utilized for cancer vaccine [5]. However, it is appropriate to include a brief summary of mRNA-based vaccines including several approaches for improving the stability and delivery of mRNA in vivo. Due to the current COVID-19 pandemic, a special emphasis is dedicated to the development of vaccines against coronaviruses including a general overview, but with the focus on RNA-based vaccines applying saRNAs for delivery [6]. The presentation includes both findings from preclinical animal models, but also the latest reports from ongoing clinical trials.

\section{Application of mRNA as Vaccines for Infectious Diseases}

Application of mRNA has been hampered by issues related to instability due to its single-stranded structure and exposure to RNases [7, 8]. For instance, incorporation of anti-reverse cap analogues (ARCAs) in the RNA sequence has both improved transcription efficiency [9] and protein expression levels [10]. Stabilization of RNA has also been achieved by engineering of the poly(A) tail at the mRNA 3' end, indicating an optimal poly(A) tail length of 120-150 nucleotides [11]. Additionally, the 5 ' end and 3 'end untranslated regions influence the mRNA stability and its transport from the nucleus [12]. Another approach relates to chemical modifications of RNA. For instance, introduction of modified uridine into the mRNA has improved mRNA stability leading to enhanced translation [13]. Although some success has been obtained with delivery of naked RNA confirmed by intramuscular mRNA injection 
resulting in reporter gene expression [14], nanoparticle (NP) and liposomal nanoparticle (LNP) formulations have demonstrated superiority, providing both protection against RNA degradation and enhanced cellular uptake [15].

In the context of mRNA-based vaccines for infectious diseases, selected examples are presented below. An optimized rabies virus glycoprotein (RABV-G) mRNA complexed with protamine was intramuscularly and intradermally administered in mice and domestic pigs, respectively [16]. The vaccinations induced potent neutralizing antibodies and follow-up studies in mice showed that the titers remained stable for at least one year. Moreover, induction of CD4+ and CD8+ T cell responses were higher than observed for licensed vaccines. The immunization also resulted in protection of mice against lethal intracerebral challenges with RABV. The neutralizing antibody titers found in domestic pigs correlated with protection in adult and newborn pigs. In another mRNA vaccine application, a single low-dose intradermal immunization with liposomeencapsulated nanoparticles carrying nucleoside-modified mRNA coding for Zika virus (ZIKV) pre-membrane and envelope glycoproteins (prM-E) elicited potent and durable neutralizing antibody responses in mice and primates [17]. Furthermore, immunization with $30 \mu \mathrm{g}$ of LNP-mRNA generated protection against ZIKV at two weeks or five months after vaccination. In primates, a single dose of $50 \mu \mathrm{g}$ LNPmRNA was sufficient to provide protection five weeks after immunization. Vaccines have also been developed against influenza virus by LNP-based delivery of mRNA encoding hemagglutinin (HA) from the H10N8 and H7N9 strains [18]. Immunizations elicited rapid and robust immune responses in mice, ferrets and primates. For instance, a single dose of H7N9 RNA provided protection of mice against lethal challenges, and also showed reduced lung viral titers in ferrets. Preliminary results from a first-in-human dose-escalation phase I trial of LNP-mRNA HA H10N8 showed only mild or moderate adverse events but very high seroconversion rates and robust prophylactic immunity [18]. In another phase I clinical trial, mRNA encoding RABV-GP was administered intradermally or intramuscularly to healthy volunteers showing safety and a reasonable tolerability profile [19]. Functional antibodies against the viral antigen could be induced and boosted when administered with a needle-free device but not when a needlesyringe was used. Most recently, mRNA-based COVID-19 vaccine candidates have been subjected to clinical trials. Preliminary results from a phase I/II study [20] with a nucleoside modified mRNA (modRNA) encapsulated in LNPs showed dose-related specific IgG and SARS-CoV-2 neutralizing antibodies with higher titers than observed in a panel of COVID-19 convalescent human sera [21]. In another phase I clinical trial [22], LNP-encapsulated Severe Acute Respiratory Syndrome-Coronavirus-2 Spike protein (SARSCoV-2 S) candidate vaccines was demonstrated generally safe and well tolerated, eliciting neutralizing antibody titers at the same or higher levels in eight volunteers compared to convalescent sera [23].

\section{Self-amplifying RNA Virus Vectors}

Vaccine development based on saRNA presents an interesting and attractive alternative to mRNA-based vaccines [5]. The common feature of saRNA viruses is their singlestranded RNA (ssRNA) genome embedded in a capsid and envelope protein structure [24]. In the case of alphaviruses and flaviviruses, the ssRNA genome is of positive polarity in contrast to measles viruses (MVs) and rhabdoviruses, which carry a negative sense ssRNA genome. In any case, the RNA genome of saRNA viruses can act directly in the cytoplasm without any need of delivery to the nucleus. In the case of positive polarity, the translation can be initiated directly from the incoming ssRNA genome [24], whereas negative sense RNA molecules require the generation of a positive strand RNA template [25]. All saRNA viruses initially express their nonstructural genes resulting in the formation of the RNA replication complex (RNA replicon), responsible for extreme RNA replication in infected host cells [24]. It has been estimated that 200 ' 000 copies of RNA are made from a single RNA molecule, providing together with strong subgenomic promoters the basis for extremely high expression levels of viral proteins. This feature has been taken advantage of in expression vectors engineered from saRNA viruses, which have been applied for mammalian and non-mammalian cell lines, primary cells and in vivo [26]. Moreover, saRNA virus vectors have been used for vaccine development both for administration of naked saRNA and liposome- or polymerencapsulated saRNA, targeting both infectious diseases and different types of cancers. In this review, the basic function of saRNA virus vectors is described, and various preclinical and clinical applications are presented.

Although efficient expression systems have been developed for alphaviruses, flaviviruses, MVs and rhabdoviruses the differences in the polarity of the ssRNA genome have required alternative engineering. Among alphaviruses, belonging to the family of Togaviruses [24], expression systems have been engineered for Semliki Forest virus (SFV) [27], Sindbis virus (SIN) [28] and Venezuelan equine encephalitis virus (VEE) [29]. Generally, alphavirus saRNA vector systems are all based on the RNA replicon with different options for replication-deficient and -proficient expression systems and the utilization of DNA-based vectors [30] (Fig. 1). The expression vector contains the nonstructural protein genes (nsP1-4) and the gene of interest inserted downstream of the 26S subgenomic promoter. RNA can be in vitro transcribed from a DNA plasmid construct and applied for direct transfection or immunization with naked or encapsulated saRNA. Alternatively, co-transfection of mammalian host cells with in vitro transcribed RNA from the expression vector and a helper vector carrying the alphavirus structural genes generates replication-deficient recombinant particles suitable for infection/immunization studies, providing high levels of transgene expression without any new viral progeny production. On the other hand, transfection of in vitro transcribed RNA from a full-length alphavirus construct including the gene of interest generates replication-proficient recombinant particles, which upon infection/immunization will produce both transgene expression and new infectious recombinant viral particles.

Moreover, DNA based alphavirus expression vectors containing a mammalian host cell compatible eukaryotic RNA polymerase II type promoter such as CMV permits direct infection/immunization studies [30].

Similar expression vector systems for delivery of recombinant particles, RNA replicons and DNA plasmids have been engineered for Kunjin virus (KUN), a member of flaviviruses [31]. In the case of KUN, foreign genes are introduced between the $\mathrm{C} 20$ core protein and the E22 envelope protein for expression as a large polyprotein, which will be processed into individual proteins (Fig. 2). Introduction of an FMDV-2A protease sequence in the KUN vector will allow removal of remaining KUN flanking regions from the 
recombinant product [32]. Virus production from KUN vectors has been facilitated by the engineering of a packaging cell line [33]. Other flaviviruses have also been subjected to the engineering of expression systems including West Nile virus $[34,35]$, yellow fever virus [36, 37], dengue virus [38, 39] and tick-borne encephalitis [40, 41].

A

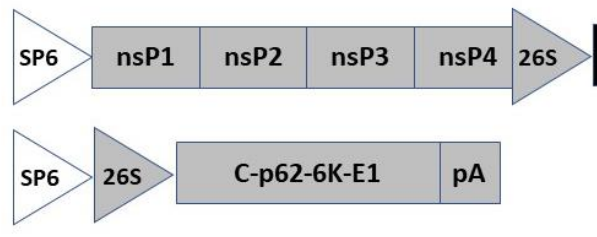

Foreign

pA

B

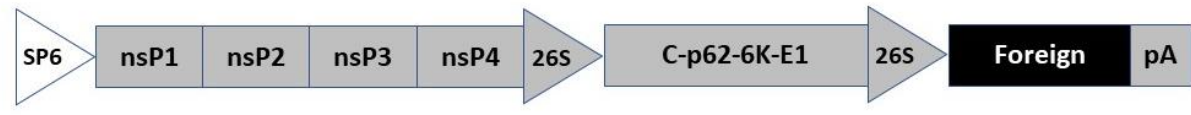

C

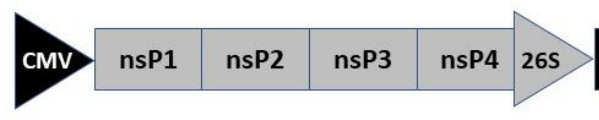

Foreign

\section{pA}

Fig. 1. Alphavirus expression systems. A. Replication-deficient system; B. Replication-proficient vector; C. DNA replicon vector. 26S, alphavirus subgenomic promoter; C-p62-6K-E1, structural protein genes; CMV, Cytomegalovirus promoter; nsP1-4, nonstructural protein genes; pA, polyadenylation signal, SP6, bacteriophage SP6 RNA polymerase promoter.

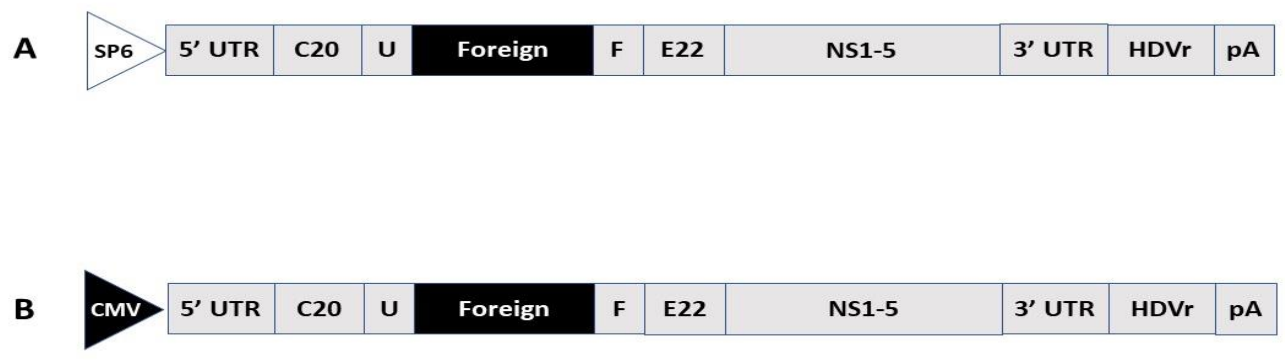

Fig. 2. Flavivirus expression systems. A. KUN vector with SP6 promoter; B. KUN vector with CMV promoter. 3' UTR, 3' end untranslated region; 5' UTR, 5' end untranslated region; C20, first 20 amino acids of KUN C protein; CMV, Cytomegalovirus promoter; E22, last 22 amino acids of KUN E protein; F, Foot-and-mouth disease virus 2A autoprotease; HDVr, Hepatitis delta virus ribozyme; pA, polyadenylation signal; SP6, bacteriophage SP6 RNA polymerase; U, mouse ubiquitin sequence.

The negative polarity of the MV genome has required the design of adequate packaging systems [42] and the application of reverse genetics [43]. In MV vectors, heterologous genes are inserted either between the phosphoprotein $(\mathrm{P})$ gene and the matrix protein $(\mathrm{M})$ gene or between the HA gene and the large protein (L) (Fig 3). A packaging cell line is utilized for production of recombinant MV particles.

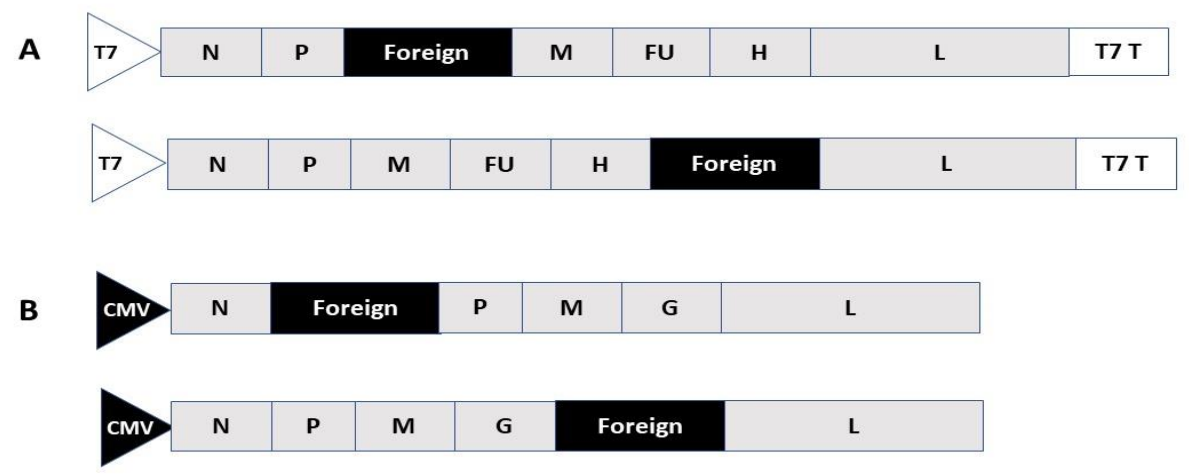

Fig. 3. A. Rhabdovirus and B. Measles virus expression systems. CMV, cytomegalovirus, Fu, fusion protein (MV); L protein (MV/RABV); $\mathrm{M}$, matrix protein (MV/RABV); N, nucleocapsid (MV/RABV); P, phosphoprotein (MV/RABV); T7, phage T7 promoter; T7T, T7 terminator. 
Similarly, rhabdoviruses have been engineered as expression vectors using reverse genetics based on a recombinant vaccinia virus vector [44, 45] (Fig. 3). Furthermore, plasmid DNA-based vesicular stomatitis virus (VSV) vectors with the $\mathrm{N}, \mathrm{P}$ and $\mathrm{L}$ genes downstream of a $\mathrm{T} 7$ RNA polymerase promoter and an internal ribosome entry site (IRES) have been designed for VSV particle production from a vaccinia-free system [46]. Rabies virus (RABV) vectors have also been constructed [47] including a vaccinia-free reverse genetics system [48].

\section{Application of Self-amplifying RNAs as Vaccines Against Infectious Diseases}

A large number of preclinical immunization studies have been conducted with saRNA virus vectors as described in Table 1. For instance, VEE particles expressing the ectodomain of the Dengue virus (DENV) E protein (E85) elicited neutralizing antibodies and $\mathrm{T}$ cell responses in four DENV serotypes after a single administration [49]. The immune response was weaker in neonatal BALB/c mice than in adult animals. However, a single vaccine administration provided protective immunity against DENV. Moreover, expression of the domain III of the DENV envelope protein 2 (DV2) from an MV vector induced robust neutralizing antibody responses [50]. It has also been demonstrated that expression of the domain II of DV1-4 form an MV vector elicited neutralizing antibodies and protected mice from challenges against four serotypes of DENV [51]. In the case of Zika virus (ZIKV), the codon-optimized prM and E genes were expressed from a VEE replicon encapsulated in highly stable nanostructured lipid carriers (NLCs) and subjected to immunization of mice, which provided protection against challenges with lethal doses of ZIKV [52]. Furthermore, VSV vectors expressing ZIKV membrane-envelope (ME) glycoproteins and Chikungunya (CHIKV) envelope polyprotein (E3-E2-6K-E1) elicited neutralizing antibodies against both ZIKV and CHIKV in wildtype and interferon-receptor-deficient A129 mice [53]. Mice receiving a single immunization also showed protection against lethal challenges with both ZIKV and CHIKV.

Due to the recent serious Ebola virus (EBOV) outbreaks in Africa, filoviruses have been the target for urgent vaccine development. For instance, subcutaneous administration of KUN virus-like particles (VLPs) expressing the EBOV glycoprotein (GP/D637L) provided complete protection in three vaccinated nonhuman primates, while one immunized and all control animals died [54]. Another study showed that macaques were protected against challenges with the West African EBOV-Makona strain after immunization with a recombinant VSV vector expressing the EBOV GP [55]. Immunization only tree or seven days before the challenge provided partial and complete protection, respectively. In another study, nonhuman primates immunized with a VSV-EBOV GP vector were resistant to challenges with three Ebola strains [56]. Another filovirus, Marburg virus (MARV), demonstrated protection in nonhuman primates after immunization with VSV-MARV-GP particles [56]. Moreover, a single intramuscular injection of VEE particles expressing the Sudan virus (SUDV) GP protected cynomolgus macaques from challenges with lethal doses of SUDV [57]. However, only partial protection against intramuscular challenges with EBOV was observed. In contrast, intramuscular co-immunization with VEE-SUDV-GP and VEEEBOV-GP resulted in complete protection against challenges with both SUDV and EBOV. Moreover, intramuscular immunization also resulted in complete protection against challenges with aerosolized SUDV. However, in this case, two vaccinations were required to achieve efficacy. In another approach, VEE particles expressing EBOV nucleoprotein (NP) administered subcutaneously to C57BL/6 mice showed protection against EBOV challenges [58]. Similarly, BALB/c mice and guinea pigs were immunized with VEE-EBOV-GP and VEE-EBOV-NP VLP [59]. Mice immunized with VEEEBOV-NP particles were protected against EBOV, whereas guinea pigs were not. However, both mice and guinea pigs coimmunized with VEE-EBOV-GP and VEE-EBOV-NP were resistant to EBOV challenges. In another approach, coexpression of EBOV-GP and EBOV-VP40 from SFV DNA replicons elicited both binding and neutralizing antibodies of higher titers compared to a Modified Vaccinia virus Ankara (MVA) vaccine [60].

Arenaviruses represent another group of highly pathogenic viruses such as Lassa virus (LASV). In this context, guinea pigs and macaques immunized with VSV vectors expressing the LASV glycoproteins provided protection against LASV strains originating from Liberia, Mali and Nigeria [61]. Additionally, expression of the wildtype LASV glycoprotein (GPCwt) and a non-cleavable $\mathrm{C}$-terminally deleted modification ( $\triangle \mathrm{GPfib})$ from individual VEE 26S subgenomic promoters induced immunogenicity and provided protection in immunized mice [62]. Interestingly, Engineered LASV-based replicon particles propagated in a Vero cell line enabled protection against LASV challenges in immunized guinea pigs [63]. Moreover, expression of Junin virus (JUNV) glycoprotein precursor (GPC) and Machupo (MACV) GPC from VEE VLPs correlated with humoral immune responses and provided complete protection against challenges with JUNV and MACV, respectively [64].

Due to the AIDS epidemic caused by the human immunodeficiency virus (HIV), lentiviruses have become attractive vaccine targets. In this context, mice immunized with SFV particles expressing the HIV-1 envelope glycoprotein (Env) were compared to a DNA vaccine and recombinant Env gp160 [65]. Superior antibody titers were observed in animals immunized with SFV particles. In another study, mice intramuscularly immunized with SFV RNA replicons expressing the HIV-1 Env gene elicited Env-specific antibody responses in four out of five mice [66]. Additionally, immunization of mice with recombinant SFV particles expressing the Indian HIV-1C env/gag/polRT genes resulted in significant $\mathrm{T}$ cell immune responses [67]. A comparison indicated that the immune responses were stronger for SFV VLPs than RNA replicons. Furthermore, in a two-dose study in $\mathrm{BALB} / \mathrm{c}$ mice with $0.2 \mu \mathrm{g}$ and $10 \mu \mathrm{g}$ of SFV DNA vectors expressing Env and a Gag-Pol-Nef fusion protein, initially lower HIV-specific $\mathrm{T}$ cell and IgG responses were discovered for the lower dose but no differences in immune responses between the doses were detected after boosting with MVA or HIV gp40 protein [68]. Moreover, immunization with the lower dose of SFV DNA elicited superior immune responses in comparison to MVA or HIV gp40 alone. In the context of utilization of RNA-based vectors, nanoparticles have been applied for the protection of RNA degradation and improvement of delivery [69, 70]. In this context, a VEE replicon with the HIV-1 glycoprotein 140 (TV1 gp140) and the 3 ' end untranslated region and the packaging signal of SIN was encapsulated in a cationic nano-emulsion consisting of squalene, 1,2-dioleoyl-3-trimethylammonium-propane (DOTAP), and sorbitan trioleate [69]. 
Table 1. Examples of preclinical immunizations against viral diseases.

\begin{tabular}{lllll}
\hline Virus & Target/Antigen & Vector Type & Finding & Ref \\
\hline \multirow{2}{*}{ Flaviviruses } & & & & \\
& & & & \\
DENV & E85 ectodomain & VEE VLPs & Dengue protection in mice & {$[49]$} \\
& DV2 & MV & Neutralizing antibodies & {$[50]$} \\
& DV1-4 & MV & Dengue protection in mice & {$[51]$} \\
Zika virus & prM. E & NLC-VEE RNA & ZIKV protection in mice & {$[52]$} \\
& M, E & VSV VLPs & ZIKV protection in mice & {$[53]$}
\end{tabular}

Filoviruses

$\begin{array}{lll}\text { EBOV } & \text { GP/D637L } & \text { KUN VLPs } \\ & \text { EBOV-GP } & \text { VSV VLPs } \\ & \text { EBOV-GP } & \text { VSV VLPs } \\ & \text { EBOV-GP } & \text { VSV-VLPs } \\ & \text { EBOV-NP } & \text { VEE VLPs } \\ & \text { EBOV-GP, NP } & \text { VEE VLPs } \\ & \text { EBOV-GP, VP40 } & \text { SFV DNA } \\ & \text { MARV-GP } & \text { VSV VLPs } \\ \text { MARV } & \text { SUDV-GP } & \text { VEE VLPs }\end{array}$

EBOV protection in $75 \%$ of primates

SUDV

SUDV-GP

SUDV protection in macaques

\section{Arenaviruses}

$\begin{array}{lll}\text { LASV } & \text { LASV-GPC } & \text { VSV VLPs } \\ & \text { LASV-GPC/ } \triangle \text { Gfib } & \text { VEE VLPs } \\ & \text { LASV-GPC } & \text { LASV VLPs } \\ \text { JUNV } & \text { JUNV-GPC } & \text { VEE VLPs } \\ \text { MACV } & \text { MACV-GPC } & \text { VEE VLPs }\end{array}$

LASV protection in guinea pigs

\section{Lentiviruses}

$\begin{array}{lllll}\text { HIV-1 } & \text { HIV-1 Env gp100 } & \text { SFV VLPs } & \text { Humoral immune responses } & {[65]} \\ \text { HIV-1 Env } & \text { SFV RNA } & \text { Antibody responses, mAbs } & {[66]} \\ \text { Env/Gag/PolRT } & \text { SFV VLPs/RNA } & \text { Antigen specific immune responses: VLPs } & {[67]} \\ & & \text { > RNA } & {[68]} \\ \text { Env/GagPolNef } & \text { SFV DNA } & \text { Superior to MVA, HIV gp40 } & {[69]} \\ \text { TV1 gp140 } & \text { VEE* RNA-NPs } & \text { Immunogenicity in macaques } & {[70]} \\ \text { Env gp120 } & \text { VEE RNA-NPs } & \text { gp120-specific antibodies } & {[71]} \\ \text { SIV } & \text { KUN VLPs } & \text { SIV protection in mice } & {[72]} \\ & \text { Env, Gag-pol, Nef, } & \text { SFV + MVA VLPs } & \text { Humoral and cellular responses } & {[73]} \\ \text { Rev, Tat } & & & \\ \text { Gag-pol } & \text { VSV + SFV VLPs } & \text { Partial SIV protection in macaques } & \end{array}$

\section{Influenza}

$\begin{array}{lll}\text { Influenza } & \text { NP } & \text { SFV VLPs } \\ \text { HA } & \text { VEE-VLPs } \\ \text { HA } & \text { SFV RNA } \\ \text { HA } & \text { VEE RNA } \\ \text { iFlu } & \text { VEE VLPs } \\ \text { NP } & \text { CSFV RNA-NPs } \\ \text { HA } & \text { SFV taRNA }\end{array}$

$\begin{array}{ll}\text { Mucosal immune response } & {[74]} \\ \text { Protection in chicken } & {[75]} \\ \text { Protection in mice } & {[76]} \\ \text { Protection in mice } & {[77]} \\ \text { Enhanced immune response } & {[78]} \\ \text { Immune response in mice } & {[79]} \\ \text { Protection in mice } & {[80]}\end{array}$




\section{Hepatotropic}

\begin{tabular}{lllll} 
HBV & HBsAg & MV & Partial protection & {$[81]$} \\
& MHB, HBcAg & SFV-G VLPs & Protection in mice by MHB & {$[82]$} \\
Alphaviruses & HBV S & SFV VLPs & Neutralization of HBV infectivity & {$[83]$} \\
CHIKV & E1-E3, C & VSV & & \\
VEE & VEE Replicon & VEE VLPs & PHIKV protection in mice & {$[53]$} \\
EEE & EEE Replicon & EEE VLPs & Protection in mice, macaques & {$[85]$} \\
WEE & WEE Replicon & WEE VLPs & Weak protection in mice, macaques & {$[85]$} \\
VEE & VEE V4020 & VEE DNA & VEE protection in mice & {$[85]$} \\
& VEE V4020 & VEE DNA & VEE protection in macaques & {$[86]$} \\
\hline
\end{tabular}

CHIKV, Chikungunya virus; CSFV, Classical swine fever virus; DENV, Dengue virus; EBOV, Ebola virus; EEE, Eastern equine encephalitis virus; JUNV, Junin virus; HA, hemagglutinin; HBV, hepatitis B virus; $\mathrm{HBcAg}$, hepatitis B core antigen; HBsAg, hepatitis B surface antigen; HIV, human immunodeficiency virus; iFlu, inactivated influenza virus; LASV, Lassa virus; MACV, Machupo virus; MARV, Marburg virus; mAbs, monoclonal antibodies; MHB, Middle surface HBV glycoprotein; NLC, nanostructured lipid carrier; NP, nucleoprotein; SFV, Semliki Forest virus; SFV-G, Semliki Forest virus with VSV G envelope; SUDV, Sudan virus; taRNA, transamplifying RNA; VEE, Venezuelan equine encephalitis virus; VEE*, VEE vector containing SIN 3' untranslated and packaging signal sequences; VLPs, virus-like particles; VSV, vesicular stomatitis virus; WEE, Western equine encephalitis virus; ZIKV, Zika virus.

Comparison of cellular immune responses of encapsulated RNA replicons and VEE VLPs in intramuscularly immunized rhesus macaques demonstrated that only $50 \mu \mathrm{g}$ of encapsulated RNA replicon provided robust immune responses superior to immunizations with VLPs. Furthermore, immunization of mice with VEE RNA replicons expressing the HIV glycoprotein 120 (gp120) encapsulated in DOTAP-based lipid nanoparticles produced high levels of recombinant protein expression for 30 days and high gp120-specific antibody titers compared to shortterm low-level expression from conventional mRNA [70]. In addition to HIV, Simian immunodeficiency virus (SIV) has also been subjected to vaccine development applying KUN-based expression [71]. Mice were immunized with four SIV gag constructs: the wildtype SIV gag gene (WT), an RNAoptimized nucleic acid sequence (DX), a human codonoptimized SIV gag gene (OPT) and wildtype matrix and capsid from gag-linked in-frame to reverse transcriptase from pol (Gag-pol). The immune response induction and protection of mice against SIV challenges was superior for the Gag-pol vaccine compared to WT, DX and OPT. In another study, only low or undetectable cytotoxic $\mathrm{T}$ cell responses were observed in macaques immunized with SFV and MVA vectors expressing SIV env, gag-pol, nef, rev and tat [72]. However, if macaques were first vaccinated with SFV and boosted with MVA, enhanced antibody responses and high $\mathrm{T}$ cell proliferation responses were obtained although protection against challenges with SIV was not achieved. In a combination immunization approach, rhesus macaques received two injections of VSV particles followed by a single administration of SFV particles expressing SIVsmE660 gag-env alone or together with rhesus granular macrophage-colony stimulating factor (GM-CSF) [73]. Four out six animals immunized with SIV gag-pol showed protection, whereas the combination with GM-CSF resulted in protection in only two out of six macaques, which indicated that
GM-CSF abrogated protection. Obviously, no protection against SIV was seen in the control group.

Influenza viruses have been targeted for vaccine development due to their contribution to recurrent annual epidemics. For instance, a systemic immune response was seen in mice immunized with SFV particles expressing the influenza virus nucleoprotein (NP) [74]. Moreover, immunization of one day or two weeks old chicken with VEE particles expressing the hemagglutinin (HA) gene from the Hong Kong influenza A isolate $(\mathrm{A} / \mathrm{HK} / 156 / 97)$ provided partial protection and complete protection, respectively [75]. Another study demonstrated that $10 \mu \mathrm{g}$ of SFV RNA replicons expressing the influenza HA gene induced significant antibody titers after a single intramuscular administration [76]. In addition, when $\mathrm{BALB} / \mathrm{c}$ mice were immunized twice with SFV-HA RNA replicons $90 \%$ were protected against influenza virus challenges. An important finding relates to the much lower doses needed for immunization in comparison to synthetic mRNA. It was demonstrated that VEE RNA expressing the influenza HA gene required only $1.25 \mu \mathrm{g}$ self-replicating RNA compared to $80 \mu \mathrm{g}$ of synthetic mRNA to achieve protection against influenza strains H1N1, H3N2 and B in immunized BALB/c mice [77]. In another approach, dendritic cells were targeted with a truncated derivative of VEE targeting dendritic cells, which elicited strong innate immune responses and sustained influenza virus-specific $\operatorname{IgG}$ antibodies in immunized BALB/c mice [78]. In another vaccine study on influenza viru the flavivirus classical swine fever virus (CSFV) RNA expressing influenza virus encapsulated in liposome nanoparticles elicited immune responses both in vitro and in vivo [79]. Additionally, a novel bipartite vector system applying trans-amplifying RNA (taRNA) has been engineered based on the SFV saRNA vector by deletion of replicon [80]. The replicase function is provided by a standard saRNA or an optimized non-replicating mRNA 
(nrRNA). The optimized nrRNA provided 10 to 100-fold higher transreplicon expression. The superiority of the nrRNA replicase compared to the saRNA replicase was most likely due to higher translational efficacy and lack of interference with cellular transition. Evaluation of the taRNA system indicated that a dose of only $50 \mathrm{ng}$ RNA was sufficient to induce neutralizing antibodies, which provided protection against influenza virus challenges.

Hepatotropic viruses have also been targeted for vaccine development. For instance, MV vectors expressing the hepatitis B virus surface antigen (HBsAg) elicited humoral immune responses in mice and rhesus monkeys also showing protection against HBV in two out of four primates [81]. Moreover, SFV RNA replicons expressing the HBV middle surface envelope glycoprotein (MHB) and the core antigen ( $\mathrm{HBcAg}$ ) were packaged into an VSV G envelope [82]. Immunization of mice generated superior CD8+ $\mathrm{T}$ cell responses in mice compared to recombinant protein- and DNA-based vaccines. A single vaccination with the SFV-G-MHB vaccine protected mice from $\mathrm{HBV}$ challenges. However, immunization with SFV-G-HBcAg failed to provide protection. Furthermore, intravenous immunization of BALB/c mice with 107 and 108 SFV particles expressing the HBV small surface (S) protein elicited antibodies reacting with both yeast-derived $S$ antigen and patient-derived $\mathrm{S}$ antigen [83]

Alphavirus replicons can also be employed for vaccine development against alphaviruses such as, particularly for VEE, western equine encephalitis virus (WEE) and eastern equine encephalitis virus (EEE) [84]. For example, in each replicon vector, the furin cleavage site between the E2 and E3 envelope proteins was deleted in VEE, WEE and EEE vectors, in vitro RNA transcribed and VLPs generated with a two-helper system [84]. Combination (VEE/WEE/EEE) or individual immunization of mice elicited strong neutralizing antibody responses. Mice were also protected against subcutaneous or aerosol challenges with VEE, WEE and EEE for 12 months. Furthermore, the VEE, WEE and EEE combination generated robust neutralizing antibody responses in macaques and provided protection against aerosol challenges with an epizootic VEE virus and a North American variety of EEE, respectively. However, poor neutralizing antibodies and only weak protection against WEE could be established when immunizations were carried out with the WEE replicon or the VEE-WEE-EEE combination. In another study, BALB/c mice were immunized with an engineered vector based on the attenuated VEE V4020 strain expressing the capsid and glycoprotein genes from two subgenomic promoters, which elicited high titers of neutralizing antibodies [85]. Vaccinated mice were protected against challenges with wildtype VEE, while all control mice died. The VEE V4020 vaccine was also evaluated in intramuscularly immunized cynomolgus macaques showing high levels of virus-neutralizing antibodies and protection against aerosol challenges with wildtype VEE [86].

\section{Vaccines Against Coronaviruses}

In the context of coronaviruses, the current COVID-19 pandemic has put further pressure on development of drugs and vaccines to treat and prevent the disease [6, 87]. Briefly, vaccine development for COVID-19 has been intensive and has accelerated to more than 120 preclinical studies and 20 clinical trials as of July 13 [88]. Vaccine development has involved inactivated and live-attenuated viruses, protein subunit and peptides, viral vectors as well as nucleic acids, which has recently been reviewed elsewhere [89].

Although the two previous outbreaks of SARS and Middle East Respiratory Syndrome (MERS) were less severe in spread and relatively quickly died out, a significant increase in vaccine development was seen [6]. The outbreaks also triggered the application of saRNA vectors (Table 2). An important issue related to vaccine development relates to the fact that SARS$\mathrm{CoV}$, the coronavirus causing SARS utilizes the angiotensin converting enzyme 2 (ACE2) as the receptor on host cells, similarly to SARS-CoV-2 causing COVID-19 [90]. On the other hand, MERS-CoV, the virus responsible for MERS, targets the dipeptidyl-peptidase 4 (DPP4) host cell receptor [91]. The SARS outbreak in 2002-2003, triggered intensive vaccine research. For instance, an attenuated recombinant VSV vector expressing SARS-CoV $\mathrm{S}$ elicited SARS-neutralizing antibodies in immunized mice [92]. Moreover, a single vaccination protected mice against challenges one or four months after the immunization and was also sufficient for controlling SARS-CoV infection. In another approach, VEE replicon particle-based vaccine candidates for SARS-CoV S and $\mathrm{N}$ proteins from the Urbani strain were evaluated [93]. Immunization of mice with VEE-SARS-CoV $\mathrm{S}$ provided complete short- and long-term protection against challenges with homologues SARS-CoV strains in both young and senescent mice. In contrast, no protection was obtained after immunization with VEE-SARS-CoV N. Related to heterologous SARS-CoV strains, the chimeric icGDO3-S virus encoding a synthetic $S$ gene of the most genetically divergent human GDO3 strain showed strong resistance to neutralization with antisera directed against the Urbani strain. Despite that, immunization with VEE-SARS-CoV $\mathrm{S}$ resulted in complete short-term protection against icGDO3-S challenges in young mice, but not in senescent animals. The age-related protection in mice was addressed in a study, where mice were immunized with VEE-SARS-CoV $S$ particles packaged with either attenuated (3014) or wildtype (3000) VEE glycoproteins [94]. It was demonstrated that aged animals immunized with the VEE 3000-based vaccine were protected against SARS-CoV, while immunization with the VEE 3014-based vaccine did not result in survival after the challenge. Furthermore, superior protection was observed in a lethal influenza challenge model. In the context of MERS-CoV, the MERS-CoV S full-length and a soluble variant (MERS-solS) were expressed from a replication-proficient $\mathrm{MV}$ vector, which both elicited robust MV- and MERS-CoV-neutralizing antibodies in mice [95]. Vaccination also provided protection against challenges with MERS-CoV. 
In spite of the favorable immune responses and protection observed in animals immunized with alphavirus particles, the potential and simplicity of utilizing RNA-based delivery has encouraged the formulation of liposome nanoparticles (LNPs) to provide protection against RNA degradation and enhanced transgene expression. In the case of saRNAs, the large size (approximately 9,500 nucleotides) further requires a delivery system for efficient cellular uptake. LNPs containing ionizable cationic lipids, phosphatidylcholine, cholesterol and PEG-lipid have demonstrated high efficacy both in vitro and in vivo and could induce robust immune responses against a model antigen [96]. Immunization with a VEE saRNA vector expressing the SARS-CoV-2 spike (S) protein encapsulated in LNPs elicited remarkably high dose-dependent SARS-CoV-2 specific antibody titers in mice [97]. Robust neutralizing antibodies against both pseudo-virus and wildtype virus were elicited. Furthermore, the neutralization was proportional to specific IgG quantities and superior to what has been seen in recovered COVID-19 patients. In another approach, the self-replicating mRNA system STARRTM has showed superiority compared to conventional mRNA delivery [98]. For example, a single dose of STARR ${ }^{\mathrm{TM}}$ saRNA encapsulated in LUNAR ${ }^{\circledR}$ liposomes induced high seroconversion rates, which were many-fold higher than observed for conventional mRNA. Moreover, higher anti-spike protein $\mathrm{IgG}$ responses were obtained, and they continued to increase at a much greater rate over the 30-day post-vaccination period.

Table 2. Vaccine studies against Coronaviruses.

\begin{tabular}{|c|c|c|c|c|}
\hline Virus & Target/Antigen & Vector Type & Finding & Ref \\
\hline \multirow{3}{*}{ SARS-CoV } & SARS-CoV S & VSV & Protection in mice & {$[92]$} \\
\hline & SARS-CoV S & VEE VLPs & Protection in mice & [93] \\
\hline & SARS-CoV S & VEE VLPs & Protection in mice & [94] \\
\hline MERS-CoV & MERS-S & MV & Protection in mice & [95] \\
\hline \multirow[t]{3}{*}{ SARS-CoV-2 } & SARS-CoV-2 S & VEE LNPs & $\begin{array}{l}\text { Robust neutralizing antibody responses, } \\
\text { superior to COVID-19 patients }\end{array}$ & [97] \\
\hline & SARS-CoV-2 S & STARRTM LUNAR® & Cellular and humoral immune responses & [98] \\
\hline & SARS-CoV-2 S & VEE LNPs & Phase I/II trial in progress & [99] \\
\hline
\end{tabular}

MERS-CoV, Middle East respiratory syndrome-coronavirus; MV, measles virus; SARS-CoV, severe acute respiratory syndromecoronavirus; VSV, vesicular stomatitis virus.

The positive findings from preclinical studies encouraged the initiation of a first-in-human randomized, placebocontrolled, observer-blind, dose-finding phase I/II clinical trial using VEE-LNPs expressing the SARS-CoV-2 S protein in healthy volunteers [99]. Initially, 18-45 years old volunteers will be included in the study with a plan to expand to volunteers to the age group of 18-75.

\section{Clinical Trials on Self-amplifying RNA-based Vaccines}

Only a relatively modest number of clinical trials have been conducted for saRNA virus vectors (Table 3). In this context, $40 \mathrm{CMV}$ seronegative healthy volunteers were subjected to a randomized, double-blind phase I trial, receiving intramuscularly or subcutaneously VEE particles expressing the CMV glycoprotein B or the fusion between CMV pp65 and IE1 proteins [100]. Both the lower dose of $1 \times 10^{7}$ infectious units (IU) and the higher dose of $1 \times 10^{8}$ IU were well tolerated with only mild to moderate local reactogenicity, minimal systemic reactogenicity and no clinically important changes in laboratory parameters. Direct IFN- $\gamma$ responses to $\mathrm{CMV}$ antigens were obtained in all vaccinated subjects. The immunization was proven to be safe eliciting neutralizing antibodies and multifunctional $\mathrm{T}$ cell responses against all three CMV antigens important for acquiring protective immunity. Moreover, a randomized, double-blind, placebo-controlled phase I trial was carried out in HIV-negative volunteers in the US and South Africa [101]. The subcutaneous immunization with escalating doses of VEE particles expressing the non-myristoylated form of the HIV-1 subtype C Gag protein was well tolerated with only modest local reactogenicity. Although five serious adverse events were reported, none of them were considered related to the vaccine administration. However, low levels of binding antibodies and $\mathrm{T}$ cell responses were discovered and only at the highest dose of $1 \times 10^{8} \mathrm{IU}$.

Due to several outbreaks in Africa, accelerated efforts have been dedicated to the development of EBOV vaccine candidates including the application of self-amplifying RNA virus vectors. In this context, 78 volunteers were immunized with one of three doses $\left(3 \times 10^{6}, 2 \times 10^{7}\right.$ or $\left.1 \times 10^{8} \mathrm{pfu}\right)$ of VSV particles expressing the glycoprotein of a Zaire EBOV strain (VSV-ZEBOV) in a phase I trial to assess safety and immunogenicity [102]. Although some minor adverse events such as injection-site pain, fatigue, myalgia and headache were observed the procedure was safe. The two highest doses elicited superior ZEBOV GP-specific antibody titers compared to the lowest dose. Moreover, higher antibody titers were observed after the second immunization although the effect decreased after six months. In any case, the prophylactic effect of the highest dose should be explored in additional clinical trials. In another phase I trial, 40 volunteers received doses of $1 \times 10^{5}$, 
$5 \times 10^{5}$ or $3 \times 10^{6}$ pfu of an attenuated VSV vector with the VSV G protein replaced by ZEBOV GP [103]. The study showed no serious adverse events and sustainable immunogenicity was established for 180 days (end of the study). Moreover, 30 healthy volunteers received $3 \times 10^{5}, 3 \times 10^{6}$ or $2 \times 10^{7}$ pfu of VSVZEBOV in a phase $I$ trial showing good tolerability and presence of EBOV-specific of neutralizing antibodies in nearly all vaccinees [104]. A follow-up study demonstrated that more than one-third of the immunized volunteers developed VSVspecific CTL responses and antibodies [105]. Furthermore, in a dose-finding, placebo-controlled, double-blind phase I/II study, the VSV-ZEBOV dose was reduced to $3 \times 10^{5} \mathrm{pfu}$, which improved tolerability, but decreased antibody responses and did not prevent vaccine-induced arthritis, dermatitis or vasculitis [106]. Also, in a randomized placebo-controlled phase II study, 1500 adults were immunized with a chimpanzee adenovirusbased vector (ChAd3-EBO-Z) and VSVAG-ZEBOV-GP in Liberia, which induced antibody responses in $70.8 \%$ and $83.7 \%$, respectively, of vaccinees compared to $2.8 \%$ in the control group receiving placebo one month after vaccinations [107]. At 12 months, $69.3 \%$ of individuals immunized with ChaAd3-EBO-Z and $79.5 \%$ vaccinated with VSVAG-ZEBOVGP generated antibody responses. In an open-label, clusterrandomized ring vaccination phase III trial 4123 individuals were assigned for immediate vaccination with VSV-ZEBOV and 3528 persons were to receive delayed vaccination [108]. No new EVD cases were discovered in the immediate vaccination group ten days after randomization. However, 16 EVD cases were registered in the delayed vaccination group confirming a vaccine efficacy of 100\%. Similarly, 2119 individuals were immediately vaccinated with a single dose of $2 \times 10^{7}$ pfu of VSV-ZEBOV and 2041 subjects were immunized 21 days after randomization in Guinea and Sierra Leone [109]. Follow-up for 84 days demonstrated substantial protection against EVD with no cases recorded 10 days after vaccination. Health care and frontline workers in the five most EVDaffected districts in Sierra Leone were vaccinated with a single intramuscular dose of $2 \times 10^{7}$ pfu of VSV-ZEBOV at enrollment or 18-24 weeks later in the individually controlled phase II/III trial STRIVE (Sierra Leone Trial to Introduce a Vaccine against Ebola) [110]. The vaccination of 8,673 individuals resulted in no vaccine-related serious adverse events and no cases of EVD were reported. Moreover, a phase III study involving 1197 individuals was conducted in Canada, Spain and the US, with a single dose or $2 \times 10^{7}$ pfu or $1 \times 10^{8}$ pfu of VSV $\triangle$ G-ZEBOV-GP [111]. The results indicated that the vaccine was safe, showing no vaccine-related severe adverse events or deaths.

Table 3. Clinical trials conducted for self-amplifying RNA viral vectors.

\begin{tabular}{|c|c|c|c|c|}
\hline Indication & Vector/Antigen & Phase & Response & Ref \\
\hline \multicolumn{5}{|l|}{ Infections } \\
\hline CMV & VEE-gB/p55-IE1 & Phase I & CMV-specific Abs & {$[100]$} \\
\hline AIDS & VEE-HIV-gag & Phase I & Modest antibody responses & {$[101]$} \\
\hline \multirow[t]{9}{*}{ EBOV } & VSV-ZEBOV & Phase I & Anti-ZEBOV Abs & [102] \\
\hline & VSV $\Delta \mathrm{G}-\mathrm{ZEBOV}$ & Phase I & Sustainable IgG titers for 180 days & [103] \\
\hline & VSV-ZEBOV & Phase I & EBOV-specific neutralizing Abs & [104] \\
\hline & VSV-ZEBOV & Phase I/II & Lower dose, improved tolerability & [106] \\
\hline & VSV $\Delta \mathrm{G}-\mathrm{ZEBOV}$ & Phase II & $\mathrm{Ab}$-response in $80 \%$ of vaccinees & [107] \\
\hline & VSV-ZEBOV & Phase III & $100 \%$ protection against EVD & [108] \\
\hline & VSV-ZEBOV & Phase III & Substantial protection against EVD & [109] \\
\hline & VSV-ZEBOV & Phase II/III & No EVD, no vaccine-related AEs & [112] \\
\hline & VSV $\Delta \mathrm{G}-\mathrm{ZEBOV}$ & Phase III & Safe, no vaccine-related AEs & [113] \\
\hline CHIK & CHIK VLPs & Phase II & Safe, well tolerated & {$[116]$} \\
\hline VEE & VEE DNA & Phase I & VEE-specific neutralizing Abs & [118] \\
\hline SARS-CoV-2 & VEE LNPs & Phase I/II & Study in progress in healthy volunteers & [99] \\
\hline
\end{tabular}

Abs, antibodies; AEs, adverse events; CEA, carcinoembryonic antigen; CHIKV, Chikungunya virus; CMV, cytomegalovirus; EBOV, Ebola virus; EVD, Ebola virus disease; HIV, human immunodeficiency virus; LNPs, liposomal nanoparticles; LipoVIL12, liposome-encapsulate SFV expressing IL-12; MV, measles virus; MVEZ, MV Edmonston-Zagreb strain; NIS, sodium iodide symporter; PSMA, prostate-specific membrane antigen; SFV, Semliki Forest virus; VEE, Venezuelan equine encephalitis virus; VLPs, virus-like particles; VSV, vesicular stomatitis virus; ZEBOV, glycoprotein of Zaire EBOV.

Alphaviruses such as CHIKV with outbreaks in the Republic of Congo [112] and Reunion [113] and VEE with periodic epidemics have occurred in humans and equines in Latin America [114] have made them feasible targets for vaccine development. Two intramuscular injections of CHIKV 28 days apart were administered to 389 healthy volunteers in a randomized, placebo-controlled, double-blind, phase II clinical trial in Haiti, Dominican Republic, Martinique, Guadeloupe and Puerto Rico [115]. The immunization was well tolerated with only mild to moderate adverse events. However, the clinical efficacy needs further clarification in phase III trials. In the context of VEE, a phase I trial was conducted in 41 healthy 
volunteers by intramuscular and intradermal electroporation of a VEE DNA replicon vector expressing the VEE E3-E2-6K-E1 genes [116]. Immunizations were carried out with $0.5 \mathrm{mg}$ and $2.0 \mathrm{mg}$ of plasmid DNA intramuscularly or $0.08 \mathrm{mg}$ or $0.3 \mathrm{mg}$ DNA intradermally and monitoring continued for 360 days. The study revealed no serious adverse events related to the vaccine or the device. Intradermal delivery was judged to be better related to acute tolerability. All vaccinees immunized intramuscularly elicited detectable VEE-neutralizing antibodies. In the case of intradermal administration, seven out of eight individuals developed VEE-neutralizing antibodies, while five out of eight subjects generated antibody responses after three vaccine injections. Furthermore, the DNA dose correlated with the magnitude of VEE-neutralizing antibody responses for both intramuscular and intradermal administration. Finally, as indicated above in the context of coronaviruses, the first-inhuman randomized, placebo-controlled, observer-blind, dosefinding phase I/II clinical trial using VEE-LNPs expressing the SARS-CoV-2 S protein has been initiated in healthy volunteers [99].

\section{CONCLUSIONS}

In the context of saRNA virus vectors, their main attractive features comprise the immediate efficient amplification of mRNA directly in the cytoplasm and the flexibility of applying delivery vectors based on RNA replicons, recombinant virus particles or VLPs and layered DNA/RNA vectors. The efficacy of self-amplifying RNA virus vectors has been confirmed for RNA replicons by comparison to immunization with synthetic mRNA, where protection of mice against influenza virus challenges was achieved with 64 times less self-amplifying VEE RNA $(1.25 \mu \mathrm{g})$ compared to $80 \mu \mathrm{g}$ of synthetic mRNA [77]. Similarly, 100- to 1000-fold lower doses of DNA replicon SIN-HSV-1-gB compared to conventional plasmid DNA was required to obtain antibody responses and protection against lethal challenges with virus in mice [117].

So far, saRNA vectors have been subjected to a large number of preclinical studies for infectious diseases (Table 1). Although not presented in this review but elsewhere in detail, different types of cancer vaccines have also been targeted by saRNA applications [5]. In the context of viral infections, such as EBOV, LASV, HIV and influenza virus, robust immune responses have been induced, providing in many cases protection against challenges with lethal doses of pathogenic viruses in animal models. Moreover, in a clinical phase I trial in healthy volunteers, modest antibodies against HIV-1 were obtained [101]. Similarly, VEE-specific neutralizing antibodies were elicited in individuals immunized with VEE in a phase I study [116]. Encouraging results have been obtained from phase III trials on EBOV in Africa demonstrating substantial protection against EVD [108, 109]. The current COVID-19 pandemic has naturally shed a new light on viral diseases and has accelerated the development of novel vaccines with the first clinical trial using saRNA in progress [99].
One limitation on the efficacy of saRNA-based vaccines is the fact that they induce strong innate host immune responses, which could limit the intensity and duration of transgene expression [118]. Minimizing IFN responses could be a useful strategy to increase vaccine potency. This could be achieved by co-administration of compounds able to block IFN responses, like for example vaccinia virus immune evasion proteins [80]. A different approach to boost saRNA vaccines has been based on in vitro evolution of RNA replicons in IFN-competent cells [119]. This strategy led to the identification of six mutations in the VEE nonstructural proteins (nsPs) that promoted subgenomic RNA expression. Replicons containing an optimal combination of mutations generated enhanced duration and expression levels in vivo. Expression of interleukin-2 (IL-2) resulted in 5.5-fold increase in intratumoral IL-2 levels and 2.1fold increase in infiltrating $\mathrm{CD} 8+\mathrm{T}$ cells in a $\mathrm{B} 16 \mathrm{~F} 10$ melanoma model, leading to significantly slower tumor growth. In addition to liposome- and polymer-based delivery strategies to provide improved delivery, protection against degradation and recognition by the host immune system $[15,69,70,79,98$, 99] attention has also been paid to delivery safety including engineering of vectors providing the highest safety standards. For instance, point mutations introduced into the SFV p62 precursor sequence prevented the cleavage of p62 into E2 and E3 proteins, which resulted in conditionally infectious particles and reduction of production of replication competent SFV particles [120]. Furthermore, split helper systems have been engineered for SFV [121], SIN [122] and VEE [123] by placing the capsid and envelope genes on separate helper vectors, eliminating the production of replication-proficient particles. In conclusion, saRNA virus vector systems provide a wide flexibility related to the use RNA replicons, recombinant VLPs or DNA replicon plasmids. The manufacturing of especially nucleic acid-based vaccines is straight forward, fast and inexpensive, which allows to rapidly target mutant and emerging viruses. This is particularly important in the current situation with the COVID-19 pandemic.

\section{ACKNOWLEDGEMENT}

This research received no external funding.

\section{CONFLICT OF INTEREST}

The author declares no conflict of interest.

\section{REFERENCES}

1. Cernescu C. Nucleic acid vaccines. Rom J Virol. 1995; 46(1-2): 69-73.

2. Ghaffarifar F. Plasmid DNA vaccines: where are we now? Drugs Today 2018; 54(5): 315-33. doi: 10.1358/dot.2018.54.5.2807864.

3. Pardi N, Hogan MJ, Porter FW, Weissman D. mRNA vaccines - a new era in vaccinology. Nat Rev Drug Discov. 2018; 17(4): 261-79. doi: 10.1038/nrd.2017.243

4. Ibraheem D, Elaissari A, Fessi H. Gene therapy and DNA delivery systems. Int J Pharm. 2014; 459(1-2): 70-83. doi: 10.1016/j.ijpharm.2014.10.059.

5. Lundstrom K. Self-amplifying RNA virus vectors: clinical applications in cancer drug delivery. Exp Opin Drug Deliv. 2019; 16: 1027-9. 
doi.org/10.1080/17425247.2019.1653851.

6. Lundstrom K. Coronaviruses Pandemic - Therapy and Vaccines. Biomedicines 2020; 8: 109; doi:10.3390/biomedicines8050109.

7. Brawerman G. Eukaryotic messenger RNA. Annu Rev Biochem. 1974; 43: $621-42$.

8. Burgess DJ. RNA stability: remember your driver. Nat Rev Genet. 2012; 13(2): 72 . doi: $10.1038 / \mathrm{nrg} 3159$.

9. Stepinski J, Waddell C, Stolarski R, Darzynkiewicz E, Rhoads RE. Synthesis and properties of mRNAs containing the novel 'anti-reverse' cap analogs 7-methyl (3'-O-methyl) GpppG and 7-methyl (33'-deoxy) GpppG, RNA 2001; 7(10): 1486-95.

10. Zohra FT, Chowdhury EH, Tada S, Hoshiba T, Akaike T. Effective delivery with enhanced translational activity synergistically accelerates mRNA-based transfection, Biochem Biophys Res Comm. 2007; 358(1): 373-8. doi: 10.1016/j.bbrc.2007.04.059.

11. Munroe D, Jacobson A. mRNA Poly(A) tail, a 3' enhancer of translational initiation. Mol Cell Biol. 1990; 10(7): 3441-55. doi: 10.1128/mcb.10.7.3441

12. van der Velden AW, Thomas AA. The role of the 5' untranslated region of an mRNA in translation regulation during development. Int $\mathrm{J}$ Biochem Cell Biol. 1999; 31(1): 87-106. doi: 10.1016/s1357-2725(98)00134-4.

13. Kariko K, Muramatsu H, Welsh FA, Ludwig J, Kato H, Akira S et al. Incorporation of pseudouridine into mRNA yields superior nonimmunogenic vector with increased translational capacity and biological stability. Mol Ther. 2008; 16(11): 1833-40. doi: 10.1038/mt.2008.200.

14. Wolff JA, Malone RW, Williams P, Chong W, Acsadi G, Jani A et al. Direct gene transfer into mouse muscle in vivo. Science 1990; 247(4949): 1465-8. doi: 10.1126/science.1690918.

15. Phua KKL, Leong KW, Nair SK. (2013). Transfection efficiency and transgene expression kinetics of mRNA delivered in naked and nanoparticle format. J Contr Release 2013; 166(3): 227-33. doi: 10.1016/j.jconrel.2012.12.029.

16. Schnee M, Vogel AB, Voss D, Petsch B, Baumhof P, Kramps T, Stitz L. An mRNA vaccine encoding rabies virus glycoprotein induces protection against lethal infection in mice and correlates of protection in adult and newborn pigs. PLoS Negl Trop Dis. 2016; 10(6): e0004746. doi: 10.1371/journal.pntd.0004746.

17. Pardi N, Hogan MJ, Pelc RS, Muramatsu H, Andersen H, DeMaso CR et al. Zika virus protection by a single low-dose nucleoside-modified mRNA vaccination. Nature 2017; 543(7644): 248-51. doi: 10.1038/nature21428.

18. Bahl K, Senn JJ, Yuzhakov O, Bulychev A, Brito LA, Hassett KJ et al. Preclinical and clinical demonstration of immunogenicity by mRNA vaccines against $\mathrm{H} 10 \mathrm{~N} 8$ and H7N9 influenza viruses. Mol Ther. 2017; 25(6): 1316-27. doi: 10.1016/j.ymthe.2017.03.035.

19. Alberer M, Gnad-Vogt U, Hong HS, Mehr KT, Bacckert L, Finak G et al. Safety and immunogenicity of a mRNA rabies vaccine in healthy adults: an open label, non-randomised, prospective, first-in-human phase 1 clinical trial. Lancet 2017; 390(10101): 1511-20. doi: 10.1016/S01406736(17)31665-3.

20. https://clinicaltrials.gov/ct2/show/NCT04368728

21. Mulligan MJ, Lyke KE, Kitchin N, Absalon J, Gurtman A, Lockhart S et al. Phase $1 / 2$ Study to Describe the Safety and Immunogenicity of a COVID-19 RNA Vaccine Candidate (BNT162b1) in Adults 18 to 55 Years of Age: Interim Report. MedRxiv. 2020; doi: https://doi.org/10.1101/2020.06.30.20142570.

22. https://clinicaltrials.gov/ct2/show/NCT04283461

23. https://investors.modernatx.com (Accessed on July 13, 2020).

24. Strauss JH, Strauss EG. The Alphaviruses: Gene Expression, Replication and Evolution. Micobiol Rev. 1994; 58(3): 491-562.

25. Banerjee AK. Transcription and Replication of Rhabdoviruses. Microbiol Rev. 1987; 51(1): 66-87.

26. Lundstrom K. RNA Viruses as Tools in Gene Therapy and Vaccine Development. Genes 2018; 10(3): 189. doi: 10.3390/genes10030189.

27. Liljestrom P, Garoff $H$. A new generation of animal cell expression vectors based on the Semliki Forest virus replicon. Biotechnology 1991; 9(12): 1356-61. doi: 10.1038/nbt1291-1356.

28. Xiong C, Levis R, Shen P, Schlesinger S, Rice CM, Huang HV. Sindbis virus: An efficient, broad host range vector for gene expression in animal cells. Science 1989; 243(4895): 1188-91. doi: 10.1126/science. 2922607.

29. Davis NL, Willis LV, Smith JF, Johnston RF. In vitro synthesis of infectious Venezuelan equine encephalitis virus RNA from a cDNA clone: Analysis of a viable deletion mutant. Virology 1989; 171(1): 189-204. doi: 10.1016/0042-6822(89)90526-6.

30. DiCiommo DP, Bremner R. Rapid, high level protein production using DNA-based Semliki Forest virus vectors. J. Biol. Chem. 1998; 273(29):
18060-6. doi: 10.1074/jbc.273.29.18060.

31. Pijlman GP, Suhrbier A, Khromykh AA. Kunjin virus replicons: An RNA-based, non-cytopathic viral vector system for protein production, vaccine and gene therapy applications. Exp Opin Biol Ther. 2006; 6(2): 134-45. doi: 10.1517/14712598.6.2.135.

32. De Felipe P. Skipping the co-expression problem: The new 2A 'CHYSEL' technology. Genet Vaccines Ther. 2004; 2, 13.

33. Khromykh AA, Varnavski AN, Westaway EG. Encapsidation of the flavivirus Kunjin replicon RNA by using a complementation system providing Kunjin virus structural proteins in trans. J Virol. 1998; 72(7): 5967-77. doi: 10.1128/JVI.72.7.5967-5977.1998.

34. Shi PY, Tilgner M, Lo MK. Construction and characterization of subgenomic replicons of New York strain of West Nile virus. Virology 2002; 296(2): 219-33. doi: 10.1006/viro.2002.1453.

35. Scholle I, Girard, YA, Zhao Q, Higgs S, Mason PW. Trans-packaged West Nile virus-like particles: Infectious properties in vitro and in infected mosquito vectors. J Virol. 2004; 78(21): 11605-14. doi: 10.1128/JVI.78.21.11605-11614.2004.

36. Molenkamp R, Kooi EA, Lucassen MA, Greve S, Thijssen JC, Spaan WJ, Bredenbeek PJ. Yellow fever virus replicons as an expression system for hepatitis C virus structural proteins. J Virol. 2003; 77(2): 1644-8. doi: 10.1128/jvi.77.2.1644-1648.2003.

37. Jones CT, Patkar CG, Kuhn RJ. Construction and applications of yellow fever virus replicons. Virology 2005; 331(2): 247-59. doi: 10.1016/j.virol.2004.10.034.

38. Jones M, Davidson A, Hibbert L, Gruenwald P, Schlaak J, Ball S, Foster GR, Jacobs M. Dengue virus inhibits alpha interferon signaling by reducing STAT2 expression. J Virol. 2005; 79(9): 5414-20. doi: 10.1128/JVI.79.9.5414-5420.2005.

39. Pang X, Zhang M, Dayton AI. Development of dengue virus type 2 replicons capable of prolonged expression in host cells. BMC Microbiol. 2001; 1: 18. doi: 10.1186/1471-2180-1-18.

40. Gherke R, Ecker M, Aberle SW, Allison SL, Heinz FX, Mandi CW. Incorporation of tick-borne encephalitis virus replicons into virus-like particles by a packaging cell line. J Virol. 2003; 77(16): 8924-33. doi: 10.1128/jvi.77.16.8924-8933.2003.

41. Hayasaka D, Yoshii K, Ueki T, Goto A, Mizutani T, Kariwa H, Iwasaki T, Gould EA, Takashima I. Sub-genomic replicons of tick-borne encephalitis virus. Arch Virol. 2004; 149: 1245-56. doi.org/10.1007/s00705-003-0262-y.

42. Radecke F, Spielhofer P, Schneider H, Kaelin K, Huber M, Dötsch C et al. Rescue of measles viruses from cloned DNA. EMBO J. 1995; 14(23): 5773-84.

43. Singh M, Cattaneo R, Billeter MA. A recombinant measles virus expressing hepatitis B surface antigen induces humoral responses in genetically modified mice. J Virol. 1999; 73(6): 4823-28. doi: 10.1128/JVI.73.6.4823-4828.1999.

44. Osakada F, Callaway EM. Design and generation of recombinant rabies virus vectors. Nat Protoc. 2013; 8(8): 1583-601. doi: 10.1038/nprot.2013.094.

45. An H, Kim GN, Kang CY. Genetically modified VSV(NJ) vector is capable of accommodating a large foreign gene insert and allows high level gene expression. Virus Res. 2013; 171(1): 168-77. doi: 10.1016/j.virusres.2012.11.007.

46. Harty RN, Brown ME, Hayes FP, Wright NT, Schnell MJ. Vaccinia virus-free recovery of vesicular stomatitis virus. J Mol Microbiol Biotechnol. 2001; 3(4): 513-7.

47. Ohara S, Inoue K, Yamada M, Yamawaki T, Koganezawa N, Tsuttsui K et al. Dual transneural tracing in the rat entorhoinal-hippocampal circuit by intracerebral injection of recombinant rabies virus vectors. Front Neuroanat. 2009; 3: 1-11. doi: 10.3389/neuro.05.001.2009.

48. Ito N, Takayama-Ito M, Yamada K, Hosokawa J, Sugiyama M, Minamoto N. Improved recovery of rabies virus from cloned cDNA using a vaccinia virus-free reverse genetics system. Microbiol Immunol. 2003; 47(8): 613-7. doi: 10.1111/j.1348-0421.2003.tb03424.x.

49. Khalil SM, Tonkin DR, Mattocks MD, Snead AT, Johnston RE, White LJ. A tetravalent alphavirus-vector based dengue vaccine provides effective immunity in an early life mouse model. Vaccine 2014; 32(32): 4068-74. doi: 10.1016/j.vaccine.2014.05.053.

50. Harahap-Carrillo IS, Ceballos-Olvera I, Reyes-Del Valle J. Immunogenic subviral particles displaying domain III of dengue 2 envelope protein vectored by measles virus. Vaccines 2015; 3(3): 503-18. doi: $10.3390 /$ vaccines 3030503 .

51. Hu HM, Chen HW, Hsiao Y, Wu SH, Chung HH, Hsieh CH et al. The successful induction of T-cell and antibody responses by a recombinant measles virus-vectored tetravalent dengue vaccine provides partial 
protection against dengue-2 infection. Hum Vaccin Immunother. 2016; 12(7): 1678-89. doi: 10.1080/21645515.2016.1143576.

52. Erasmus JH, Khandhar AP, Guderian J, Granger B, Archer J, Archer M et al. A nanostructured lipid carrier for delivery of a replicating viral RNA provides single, low-dose protection against Zika. Mol Ther. 2018; 26(10): 2507-22. doi: 10.1016/j.ymthe.2018.07.010.

53. Chattopadhyay A, Aquilar PV, Bopp NE, Yarovinsky TO, Weaver SC, Rose JK. A recombinant virus vaccine that protects both against Chikungunya and Zika virus infections. Vaccine 2018; 36(27): 3894-900. doi: 10.1016/j.vaccine.2018.05.095.

54. Pyankov OV, Bodnev SA, Pyankova OG, Solodkyi VV, Pyankov SA, Setoh YX et al. A Kunjin replicon virus-like vaccine provides protection against Ebola virus infection in nonhuman primates. J Infect Dis. 2015; 212(Suppl. S2): S368-71. doi: 10.1093/infdis/jiv019.

55. Marzi A, Robertson SJ, Haddock E, Feldmann F, Hanley PW, Scott D-P et al. Ebola vaccine. VSV-EBOV rapidly protects macaques against infection with the 2014/2015 Ebola virus outbreak strain. Science 2015; 349(6249): 739-42. doi: 10.1126/science.aab3920.

56. Geisbert TW, Feldmann H. Recombinant vesicular stomatitis virusbased vaccines against Ebola and Marburg infections. J Infect Dis. 2011; 204(Suppl. S3): S1075-81. doi: 10.1093/infdis/jir349.

57. Herbert AS, Kuehne AI, Barth JF, Ortiz RA, Nichols DK, Zak SE et al. Venezuelan equine encephalitis virus replicon particle vaccine protects nonhuman primates from intramuscular and aerosol challenge with ebolavirus. J Virol. 2013; 87(9): 4852-64. doi: 10.1128/JVI.03361-12.

58. Wilson JA, Hart MK. Protection from Ebola virus mediated by cytotoxic T-lymphocytes specific for the viral nucleoprotein. J. Virol. 2001; 75(6): 2660-4. doi: 10.1128/JVI.75.6.2660-2664.2001.

59. Pushko P, Bray M, Ludwig GV, Parker M, Schmaljohn A, Sanchez A et al. Recombinant RNA replicons derived from attenuated Venezuelan equine encephalitis virus protect guinea pigs and mice from Ebola hemorrhagic fever virus. Vaccine 2000; 19(1): 142-53. doi: 10.1016/s0264410x(00)00113-4

60. Öhlund P, Garcia-Arriaza J, Zusinaite E, Szurgot I, Mànnik A, Kraus A et al. DNA-launched RNA replicon vaccines induce potent anti-Ebola immune responses that can be further improved by a recombinant MVA boost. Sci. Rep. 2018; 8(1): 12459. doi: 10.1038/s41598-018-31003-6.

61.Safronetz D, Mire C, Rosenke K, Feldmann F, Haddock E, Geissbert T et al. A recombinant vesicular stomatitis virus-based Lassa fever vaccine protects guinea pigs and macaques against challenge with geographically and genetically distinct Lassa viruses. PLoS Negl Trop Dis. 2015; 9(4): e0003736. doi: 10.1371/journal.pntd.0003736.

62. Wang M, Jokinen J, Tretvakova I, Pushko P, Lukashevich IS. Alphavirus vector-based replicon particles expressing multivalent crossprotective Lassa virus glycoproteins. Vaccine 2018; 36(5): 683-90. doi: 10.1016/j.vaccine.2017.12.046.

63. Kainulainen MH, Spengler JR, Welch SR, Coleman-McCray JD, Harmon JR, Klena JD et al. Use of a scalable replicon-particle vaccine to protect against lethal Lassa virus infection in the guinea pig model. J Infect Dis. 2018; 217(12): 1957-66. doi: 10.1093/infdis/jiy123.

64. Johnson DM, Jokinen JD, Wang M, Pfeiffer T, Tretyakova I, Carrion R et al. Bivalent Junin and Machupo experimental vaccine based on alphavirus RNA replicon vector. Vaccine 2020; 38(14): 2949-59. doi: 10.1016/j.vaccine.2020.02.053.

65. Brand D, Lemiale F, Turbica I, Buzelay L, Brunet S, Barin F. Comparative analysis of humoral immune responses to HIV type 1 envelope glycoproteins in mice immunized with a DNA vaccine, recombinant Semliki Forest virus RNA, or recombinant Semliki Forest virus particles. AIDS Res Hum Retroviruses 1998; 14(15): 1369-77. doi: 10.1089/aid.1998.14.1369.

66. Giraud A, Ataman-Onal Y, Battail N. Generation of monoclonal antibodies to native human immunodeficiency virus type 1 envelope glycoprotein by immunization of mice with naked RNA. J Virol Methods 1999; 79(1): 75-84. doi: 10.1016/s0166-0934(99)00009-9.

67. Ajbani SP, Velhal SM, Kadam RB, Patel VV. Lundstrom K, Bandivdekar AH. Immunogenicity of virus-like Semliki Forest virus replicon particles expressing Indian HIV-1C gag, env and pol RT genes. Immunol Lett. 2017; 190: 221-32. doi: 10.1016/j.imlet.2017.08.019.

68. Knudsen ML, Ljungberg K, Tatoud R, Weber J, Esteban M, Liljestrom P. Alphavirus replicon DNA expressing HIV antigens is an excellent prime for boosting with recombinant modified vaccinia Ankara (MVA) or with HIV gp140 protein antigen. PLoS One 2015; 10(2): e0117042. doi: 10.1371/journal.pone.0117042.

69. Bogers WM, Oostermeijer H, Mooij P, Koopman G, Verschoor EJ, Davis D et al. Potent immune responses in rhesus macaques induced by nonviral delivery of self-amplifying RNA vaccine expressing HIV type 1 envelope with a cationic emulsion. J Infect Dis. 2015; 211(6): 947-55. doi: 10.1093/infdis/jiu522.

70. Melo M, Porter E, Zhang Y, Silva M, Li N, Dobosh B et al. Immunogenicity of RNA Replicons Encoding HIV Env Immunogens Designed for Self-Assembly into Nanoparticles. Mol Ther. 2019; 27(12): 2080-90. doi: 10.1016/j.ymthe.2019.08.007.

71. Anraku I, Mokhonov VV, Rattanasena P, Mokhonova EI, Leung J, Pijlman $\mathrm{G}$ et al. Kunjin replicon-based simian immunodeficiency virus gag vaccines. Vaccine 2008; 26(26): 3268-76. doi: 10.1016/j.vaccine.2008.04.001.

72. Nilsson C, Mäkitalo B, Berglund P, Bex F, Liljeström P, Sutter G. Enhanced simian immunodeficiency virus-specific immune responses in macaques induced by priming with recombinant Semliki Forest virus and boosting with modified vaccinia virus Ankara. Vaccine 2001; 19(25-26): 3526-36. doi: 10.1016/s0264-410x(01)00034-2.

73. Gambhira R, Keele BF, Schell JB, Hunter MJ, Dufour JP, Montefiori $\mathrm{DC}$ et al. Transmitter/founder simian immunodeficiency virus envelope sequences in vesicular stomatitis and Semliki Forest virus vector immunized rhesus macaques. PLoS One 2014; 9(10): e109678. doi: 10.1371/journal.pone.0109678.

74. Malone JG, Berglund PJ, Liljestrom P, Rhodes GH, Malone RW. Mucosal immune responses associated with polynucleotide vaccination. Behring Inst Mitt. 1997; 98: 63-72.

75. Schultz-Cherry S, Dybing JK, Davis NL, Williamson C, Suarez $\mathrm{DL}$, Johnston $\mathrm{R}$ et al. Influenza virus (A/HK/156/97) hemagglutinin expressed by an alphavirus replicon system protects against lethal infection with Hong Kong-origin H5N1 viruses. Virology 2000; 278(1): 55-59. doi: 10.1006 /viro.2000.0635.

76. Fleeton MN, Chen M, Berglund P, Rhodes G, Parker SE, Murphy M et al. Self-replicative RNA vaccines elicit protection against influenza A virus, respiratory syncytial virus, and a tickborne encephalitis virus. J Infect Dis. 2001; 183(9): 1395-98. doi: 10.1086/319857.

77. Vogel AB, Lambert L, Kinnear E, Busse D, Erbar S, Reufer KC et al. Self-amplifying RNA vaccines give equivalent protection against influenza to mRNA vaccines but at much lower doses. Mol Ther. 2018; 26(2): 44655. doi: 10.1016/j.ymthe.2017.11.017.

78. Khalil SM, Tonkin DR, Snead AT, Parks GD, Johnston RE, White LJ. An alphavirus-based adjuvant enhances serum and mucosal antibodies, $\mathrm{T}$ cells and protective immunity to influenza virus in neonatal mice. J Virol, 2014; 88(16): 9182-96. doi: 10.1128/JVI.00327-14.

79. Englezou PC, Sapet C, Démoulins T, Milona P, Ebensen T, Schulze K. Self-amplifying replicon RNA delivery to dendritic cells by cationic lipids. Mol. Ther Nucl Acids 2018; 12: 118-34. doi: 10.1016/j.omtn.2018.04.019. 80. Beissert T, Perkovic M, Vogel A, Erbar S, Walzer KC, Hempel T et al. A Trans-amplifying RNA Vaccine Strategy for Induction of Potent Protective Immunity. Mol Ther. 2020; 28(1): 119-128. doi: 10.1016/j.ymthe.2019.09.009.

81. Reyes del Valle J, Devaux P, Hodge G, Wegner NJ, McChesney MB, Cattaneo R. A vectored measles virus induces hepatitis B surface antigen antibodies while protecting macaques against virus challenge. J Virol. 2007; 81(19): 10597-605. doi: 10.1128/JVI.00923-07.

82. Reynolds TD, Buonocore L, Rose NF, Rose JK, Robek MD. Virus-like vesicle-based therapeutic vaccine vectors for chronic hepatis $\mathrm{B}$ virus infection. J Virol. 2015; 89(20): 10407-415. doi: 10.1128/JVI.01184-15. 83. Niedre-Otomere B, Bogdanova A, Skrastina D, Zajakina A, Bruvere R, Ose $\mathrm{V}$ et al. Recombinant Semliki Forest virus vectors encoding hepatitis B small surface and pre-S1 antigens induced broadly reactive neutralizing antibodies. J Viral Hepat. 2012; 19(9): 664-73. doi: 10.1111/j.13652893.2012.01594.x.

84. Reed DS, Glass PJ, Bakken RR, Barth JF, Lind CM, da Silva L et al. Combined alphavirus replicon particle vaccine induces durable and crossprotective immune responses against equine encephalitis virus. J Virol. 2014; 88(20): 12077-86. doi: 10.1128/JVI.01406-14.

85. Tretyakova I, Tibbens A, Jokinen JD, Johnson DM, Lukashevich JS, Pushko P. Novel DNA-launched Venezuelan equine encephalitis virus vaccine with rearranged genome. Vaccine 2019; 37(25): 3317-25. doi: 10.1016/j.vaccine.2019.04.072.

86. Tretyakova I, Plante KS, Rossi SL, Lawrence WS, Peel JE, Gudjohnsen $S$ et al. Venezuelan equine encephalitis vaccine with rearranged genome resists reversion and protects non-human primates from viremia after aerosol challenge. Vaccine 2020; 38(17): 3378-86. doi: 10.1016/j.vaccine.2020.02.007.

87. Pascarella G, Strumia A, Piliego C, Bruno F, Del Buono R, Costa F et al. COVID-19 diagnosis and management: a comprehensive review. J. Intern. Med. 2020; 288(2): 192-206. doi: 10.1111/joim.13091.

88. https://www.who.int/blueprint/priority-diseases/key-action/novel- 
coronavirus-landscape-ncov.pdf (Accessed on July 13, 2020)

89. Lundstrom K. Coronavirus vaccines. Front Genome Edit. 2020, in press

90. Li W, Moore MJ, Vasilieva N, Sui J, Wong SK, Berne MA et al. Angiotensin-converting enzyme 2 is a functional receptor for the SARS coronavirus. Nature 2003; 426(6965): 450-4. doi: 10.1038/nature02145. 91. van Doremalen N, Miazgowicz KL, Milne-Price S, Bushmaker T, Robertson S, Scott D et al. Host species restriction of Middle East respiratory syndrome coronavirus through its receptor dipeptidyl peptidase 4. J. Virol. 2014; 88(16): 9220-32. doi: 10.1128/JVI.00676-14.

92. Kapadia SU, Rose JK, Lamirande E, Vogel L, Subbarao K, Roberts A. Long-term protection from SARS coronavirus infection conferred by a single immunization with an attenuated VSV-based vaccine. Virology 2005; 340(2): 174-82. doi: 10.1016/j.virol.2005.06.016.

93. Deming D, Sheahan T, Heise M, Yount B, Davis N, Sims A et al. Vaccine efficacy in senescent mice challenged with recombinant SARSCoV bearing epidemic and zoonotic spike variants. PLoS Med. 2006; 3(12): e525. doi: 10.1371/journal.pmed.0030525.

94. Sheahan T, Whitmore A, Long K, Ferris M, Rockx B, Funkhouser B et al. Successful vaccination strategies that protect aged mice from lethal challenge from influenza virus and heterologous severe acute respiratory syndrome coronavirus. J Virol. 2011; 85(1): 217-30. doi: 10.1128/JVI.01805-10.

95. Malczyk AH, Kupke A, Prüfer S, Scheuplein VA, Hutzler S, Kreuz D. A highly immunogenic and protective Middle East respiratory syndrome coronavirus vaccine based on a recombinant measles virus vaccine platform. J Virol. 2015; 89(22): 11654-67. doi: 10.1128/JVI.01815-15. 96. Blakney AK, McKay PF, Yus BI, Aldon Y, Shattock RJ. Inside out: optimization of lipid nanoparticle formulations for exterior complexation and in vivo delivery of saRNA. Gene Ther. 2019; 26(9): 363-72. doi: 10.1038/s41434-019-0095-2.

97. McKay PF, Hu K, Blakney AK, Samnuan K, Brown JC, Penn R et al. Self-amplifying RNA SARS-CoV-2 lipid nanoparticle vaccine candidate induces high neutralizing antibody titers in mice. Nat Commun. 2020; 11(1): 3523. doi: 10.1038/s41467-020-17409-9.

98. https://ir.arcturusrx.com/news-releases/news-release-details/arcturusreports-additional-supportive-preclinical-data-its (Accessed July 14, 2020). 99. http://www.isrctn.com/ISRCTN17072692

100. Bernstein DI, Reap EA, Katen K, Watson A, Smith K, Norberg P. Randomized, double-blind, phase I trial on an alphavirus replicon vaccine for cytomegalovirus in CMV negative volunteers. Vaccine 2010; 28(2): 484-93. doi: 10.1016/j.vaccine.2009.09.135.

101. Wecker M, Gilbert P, Russell N, Hural J, Allen M, Pensiero M. Phase I safety and immunogenicity evaluations of an alphavirus replicon HIV-1 subtype $\mathrm{C}$ gag vaccine in healthy HIV-1-uninfected adults. Clin Vaccine Immunol. 2012; 19(10): 1651-60. doi: 10.1128/CVI.00258-12.

102. Regules JA, Beigel JH, Paolino KM, Voell J, Castellano AR, Hu Z et al. A recombinant vesicular stomatitis virus ebola vaccine. N Engl J Med. 2017; 376(4): 330-41. doi: 10.1056/NEJMoa1414216.

103. El Sherif MS, Brown C, MacKinnon-Cameron D, Li L, Racine T, Alimonti $\mathrm{J}$ et al. Assessing the safety and immunogenicity of recombinant vesicular stomatitis virus Ebola vaccine in healthy adults: A randomized clinical trial. CMAJ 2017; 189(24): E819-27. doi: 10.1503/cmaj.170074. 104. Dahlke C, Kasonta R, Lunemann S, Krahling V, Zinser ME, Biedenkopf $\mathrm{N}$ et al. Dose-dependent T-cell dynamics and cytokine cascade following rVSV-ZEBOV immunization. EBioMedicine 2017; 19: 107-18. doi: 10.1016/j.ebiom.2017.03.045.

105. Poetsch JH, Dahlke C, Zinser ME, Kasonta R, Lunemann S, Rechtien A et al. Detectable Vesicular Stomatitis Virus (VSV)-Specific Humoral and Cellular Immune Responses Following VSV-Ebola Virus Vaccination in Humans. J Infect Dis. 2019; 219(4): 556-61. doi: 10.1093/infdis/jiy565. 106. Huttner A, Dayer JA, Yerly S, Combescure C, Auderset F, Desmeules J. The effect of dose on the safety and immunogenicity of the VSV Ebola candidate vaccine: A randomised double-blind, placebo-controlled phase 1/2 trial. Lancet Infect. Dis. 2015; 15(10): 1156-66. doi: 10.1016/S1473-
3099(15)00154-1.

107. Kennedy SB, Bolay F, Kieh M, Grandits G, Badio M, Ballou R et al. Phase 2 placebo-controlled trial of two vaccines to prevent ebola in Liberia. N Eng J Med. 2017; 377(15): 1438-47. doi: 10.1056/NEJMoa1614067. 108. Henao-Restrepo AM, Longini IM, Egger M, Dean NE, Edmunds WJ, Camacho A et al. Efficacy and effectiveness of an rVSV-vectored vaccine expressing Ebola surface glycoprotein: Interim results from the Guinea ring vaccination cluster-randomised trial. Lancet 2015; 386(9996): 857-66. doi: 10.1016/S0140-6736(15)61117-5.

109. Henao-Restrepo AM, Camacho A, Longini IM, Watson CH, Edmunds WJ, Egger $M$ et al. Efficacy and effectiveness of an rVSV-vectored vaccine in preventing Ebola virus disease: Final results from the Guinea ring vaccination, open-label, cluster-randomised trial (Ebola Ca Suffit!). Lancet 2017; 389(10068): 505-18. doi: 10.1016/S0140-6736(16)32621-6.

110. Widdowson M, Schrag S, Carter R, Carr W, Legardy-Williams J, Gibson L et al. Implementing an Ebola vaccine study-Sierra Leone. MMWR Suppl. 2016; 65(3): 98-106. doi: 10.15585/mmwr.su6503a14.

111. Halperin SA, Arribas JR, Rupp R, Andrews CP, Chu L, Das R et al. Six-month safety data of recombinant vesicular stomatitis virus-zaire ebola virus envelope glycoprotein vaccine in a phase 3 double-blind, placebocontrolled randomized study in healthy adults. J Infect Dis. 2017; 215(12): 1789-98. doi: 10.1093/infdis/jix189.

112. Kelvin AA. Outbreak of Chikungunya in the Republic of Congo and the global picture. J Infect Dev Ctries. 2011; 5(6): 441-4.

113. Jansen KA. The 2005-2007 Chikungunya epidemic in Reunion: Ambiguous etiologies, memories, and meaning-making. Med Anthropol. 2013; 32(2): 174-89. doi: 10.1080/01459740.2012.679981.

114. Weaver SC, Salas R, Rico-Hesse R, Ludwig GV, Oberste MS, Boshell $\mathrm{J}$ et al. Re-emergence of epidemic Venezuelan equine encephalomyelitis in South America. VEE Study Group. Lancet 1996; 348(9025): 436-40. doi: 10.1016/s0140-6736(96)02275-1.

115. Chen GL, Coates EE, Plummer SH, Carter CA, Berkowitz N, ConanCibotti $\mathrm{M}$ et al. Effect of a Chikungunya Virus-Like Particle Vaccine on Safety and Tolerability Outcomes: A Randomized Clinical Trial. JAMA 2020; 323(14): 1369-77. doi: 10.1001/jama.2020.2477.

116. Hannaman D, Dupuy LC, Ellefsen B, Schmaljohn CS. A Phase 1 clinical trial of a DNA vaccine for Venezuelan equine encephalitis delivered by intramuscular or intradermal electroporation. Vaccine 2016; 34(31): 3607-12. doi: 10.1016/j.vaccine.2016.04.077.

117. Hariharan MJ, Driver DA, Townsend K, Brumm D, Polo JM, Belli BA et al. DNA immunization against herpes simplex virus: Enhanced efficacy using a Sindbis virus-based vector. J Virol. 1998; 72(2): 950-8. doi: 10.1128/JVI.72.2.950-958.1998.

118. Leitner WW, Hwang LN, deVeer MJ, Zhou A, Silverman RH, Williams BR et al. Alphavirus-based DNA vaccine breaks immunological tolerance by activating innate antiviral pathways. Nat Med. 2003; 9(1): 339. doi: $10.1038 / \mathrm{nm} 813$.

119. Li Y, Teague B, Zhang Y, Su Z, Porter E, Dobosh B et al. In vitro evolution of enhanced RNA replicons for immunotherapy. Sci Rep. 2019; 9(1): 6932. doi: 10.1038/s41598-019-43422-0.

120. Berglund P, Sjöberg M, Garoff H, Atkins GJ, Sheahan BJ, Liljeström P. Semliki Forest virus expression system: Production of conditionally infectious recombinant particles. Biotechnology 1993; 11(8): 916-20. doi: 10.1038/nbt0893-916.

121. Smerdou C, Liljeström P. Two-helper system for production of recombinant Semliki Forest virus particles. J. Virol. 1999; 73(2): 1092-8. doi: 10.1128/JVI.73.2.1092-1098.1999.

122. Ketola A, Schlesinger S, Wahlfors J. Properties of Sindbis virus vectors produced with a chimeric split helper system. Int J Mol Med. 2005; 15(6): 999-1003.

123. Pushko P, Parker M, Ludwig GV, Davis NL, Johnston RE, Smith JF. Replicon-helper systems from attenuated Venezuelan equine encephalitis virus: expression of heterologous genes in vitro and immunization against heterologous pathogens in vivo. Virology 1997; 239(2): 389-401. doi: 10.1006/viro.1997.8878. 